\title{
Semantic facilitation and translation priming effects in Chinese-English bilinguals
}

\author{
HSUAN-CHIH CHEN and MAN-LAI NG \\ The Chinese University of Hong Kong, Shatin, Hong Kong
}

\begin{abstract}
In two experiments, semantic facilitation and translation priming effects in Chinese-English bilingual speakers were demonstrated with a lexical decision task. A 300-msec stimulus-onset asynchrony (SOA) was used between display of the prime and the target item. Experiment 1 showed that subjects' lexical decision responses were facilitated to a greater extent when primed by a translation equivalent than a semantically related between-language word. In Experiment 2, we found that pictorial, between-language, and within-language primes produced comparable effects of semantic facilitation. These results are in line with the hypothesis that lexical items in different languages and pictures are processed by means of an amodal conceptual system.
\end{abstract}

In recent years, there has been an increasing interest in bilingual or multilingual processing (see, e.g., Grosjean, 1982; Hornby, 1977; Snodgrass, 1984; Vaid, 1986), not only because learning to use more than one language is very common in real life, but also because it involves very complex cognitive activities. A fundamental research topic in this area concerns lexical processing by bilingual subjects. This topic is related to important theoretical issues of the nature of the lexicon(s) of the bilingual speaker and the relationship between the internal processing of a concept and its surface form.

Recently, Kirsner, Smith, Lockhart, King, and Jain (1984) conducted a series of experiments to test different models of lexical representation and processing in bilingual speakers. The three major models tested were the word-association model, the word-interconnection model, and the concept-mediation model. Illustrations of these three models are shown in Figure 1. The word-association model proposes that translation equivalents in the two languages of a bilingual speaker are directly connected to each other. Semantically related words in a given language are also directly linked. However, semantically related words in the two languages are not directly connected, but rather indirectly connected through corresponding translation equivalents. The word-interconnection model postulates that all words in the two languages, including both translation equivalents and semantically related words, are directly connected to each other. The conceptmediation model, in contrast to the other two models, assumes that neither within-language nor between-language words are directly connected; rather, they are all linked

This research was supported by a Faculty Research Grant from The Chinese University of Hong Kong to Hsuan-Chih Chen. We thank M. J. Chen, Ira Fischler, Don Scarborough, James Chumbley, and two anonymous reviewers for critical comments and helpful suggestions. Correspondence concerning this article should be addressed to Hsuan-Chih Chen, Department of Psychology, The Chinese University of Hong Kong, Shatin, N.T., Hong Kong. to their nonlinguistic concepts or meanings. That is, entries in the two lexicons of a bilingual speaker are linked at the amodal conceptual level, but not at the languagespecific lexical level.

To test these models, Kirsner et al. (1984) used various lexical decision priming paradigms. In the first three experiments, they adopted a repetition/translation priming paradigm in which words in one language were first presented in the study session and were later presented either in the original form (i.e., repetitions) or in the other language (i.e., translations) in the test session (see, e.g., Feldman \& Moskovljevic, 1987; Kirsner, 1986; Scarborough, Cortese, \& Scarborough, 1977, for discussions of the repetition priming procedure). The idea was that if translation equivalents are represented in languagespecific forms, then the repetition and translation conditions should result in different patterns of results. The general results showed that the processing of a concept could be affected by how the concept was presented or activated: Words repeated in the same language (i.e., the repetition condition), but not those repeated in the different language (i.e., the translation condition), resulted in shorter lexical decision times than did unrepeated new words (see, e.g., Kirsner, Brown, Abrol, Chadha, \& Sharma, 1980; Scarborough, Gerard, \& Cortese, 1984, for similar findings). In other words, lexical recognition could be generally facilitated by a represented identical item, but not by a functionally equivalent translation item. These results, according to Kirsner et al. (1984), seemed to suggest that there are language-specific stores for lexical representations in bilingual speakers.

Kirsner et al. (1984) conducted two additional experiments to explore whether the processing of semantically related concepts would be differently affected by how these concepts are activated. In these experiments, a semantic priming paradigm (see, e.g., Fischler, 1977; Neely, 1977) was used in which semantically related or unrelated words were displayed successively or simultaneously. The results revealed substantial semantic facili- 

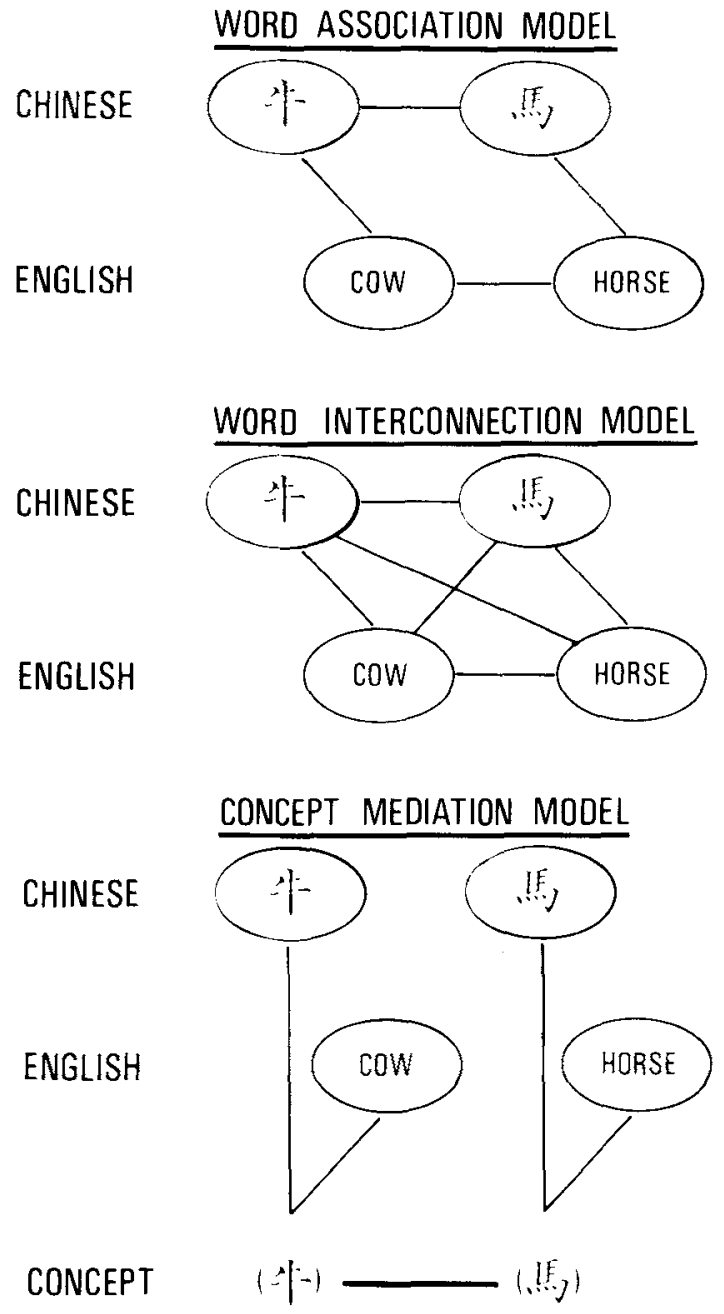

Figure 1. Three major models of lexical organization in bilinguals tested in Kirsner, Smith, Lockhart, King, \& Jain (1984).

tation from both between- and within-language primes. Specifically, in Experiment 4, using English-Hindi bilingual speakers, they found evidence of equal semantic priming effects within and across languages, whereas in Experiment 5, using English-French bilingual speakers, they found a greater facilitative effect in the withinlanguage condition than in the between-language condition. These findings suggest that although different concepts can be expressed in various language forms, they are mentally represented in an integrated system. These semantic priming effects, especially those from Experiment 4 , unlike the mentioned repetition effects, could not be accounted for by the word-association model. Consequently, this model was rejected. Because the wordinterconnection model and the concept-mediation model could not be distinguished from each other on the basis of the obtained results, Kirsner et al. (1984) suggested that further research was needed to test these models.

Kirsner et al. (1984) attributed the semantic facilitation effects and the repetition effects to mental mechanisms operating at different levels (i.e., the lexical vs. the conceptual level, respectively). Because the repetition effects were relatively long lasting (i.e., two repeated items were separated by many intervening items, and the average interval was about $33 \mathrm{~min}$ ), whereas the semantic facilitation effects were rather short-lived (i.e., these effects disappeared when two related concepts were separated by two intervening items), Kirsner et al. suggested that lexical or pathway activation is relatively persistent, but that activation among internal representations is very transient. Taken together, the semantic facilitation and repetition effects led them to conclude that "although the unit of lexical representation in bilinguals is language specific, the units function in an integrated network" (p. 519).

More recently, Schwanenflugel and Rey (1986) have reported evidence for rejecting both the word-association and the word-interconnection models. They studied Spanish-English bilingual subjects with a lexical decision task. Using short prime-target intervals (100- and 300 -msec SOAs), Schwanenflugel and Rey found that the semantic facilitation effect resulting from a betweenlanguage prime and that from a within-language prime were highly comparable. Furthermore, these priming effects were not affected by the semantic distance between the prime and the target. These findings are more consistent with the concept-mediation model than with the wordinterconnection or word-association model and are not completely consistent with the results of Kirsner et al. (1984), who found equivalent associative priming effects in Experiment 4, but larger within- than between-language priming effects in Experiment 5.

The preceding review indicates that the results of previous research on primed lexical decisions made by bilingual speakers are not very consistent. The present experiments were designed to investigate this issue further with Chinese-English bilingual speakers. Most of the previous research on bilingual processing has employed subjects whose first and second languages derive from the same Indo-European family. The Chinese language, however, differs on important orthographic and linguistic dimensions from the languages of the Indo-European family. Thus, the use of Chinese-English bilingual speakers, who have distinctively different first and second languages, may provide useful information about linguistic universals.

The present study comprised two experiments. In Experiment 1, we compared two types of between-language priming conditions: translation and semantic priming. Experiment 2 was designed in order to test the wordinterconnection and the concept-mediation models. The word-association model, on the other hand, was not involved in the present study, because it has been consistently rejected on the basis of findings in previous research (e.g., Kirsner et al., 1984; Schwanenflugel \& Rey, 1986). Following Schwanenflugel and Rey and Kirsner et al., the lexical decision priming paradigm was used in the present experiments. 


\section{EXPERIMENT 1}

Several studies on lexical decision priming have failed to find a translation facilitation effect with relatively long priming intervals of $10 \mathrm{~min}$ or more (e.g., Kirsner et al., 1980; Kirsner et al., 1984, Experiments 1 and 3; Scarborough et al., 1984). On the other hand, a reliable between-language semantic facilitation effect has been reported in studies with relatively short priming intervals of $300 \mathrm{msec}$ or less (e.g., Kirsner et al., 1984; Schwanenflugel "\& Rey, 1986). These results suggest that the presence of a between-language transfer may be dependent upon the time interval between the two presentations, and that the between-language transfer is very transient (see, e.g., Kirsner et al., 1984; Scarborough et al., 1984). Following this rationale, one should be able to demonstrate a translation facilitation effect with a short priming interval similar to that used in previous studies of semantic priming. This prediction has not been tested in previous studies, so Experiment 1 was designed to test it.

Experiment 1 also included a between-language semantic priming condition to replicate the between-language semantic facilitation found in previous studies (e.g., Kirsner et al., 1984; Schwanenflugel \& Rey, 1986), and also to permit a comparison with the possible effect of translation priming. This comparison was intended to provide additional new information about between-language transfer in bilingual speakers. Kirsner et al., for example, have suggested that comparing the translation and betweenlanguage semantic priming effects can help to differentiate between the concept-mediation and the word interconnection models. Specifically, the concept-mediation model predicts that the translation priming effect should be stronger than the semantic priming effect. This is because in the translation priming condition, only a single concept node would be activated, whereas in the semantic priming condition two concept nodes need to be activated. On the other hand, the word-interconnection model reviewed in the study of Kirsner et al. would predict that these two effects should not be different from each other, because the words in the two languages of a bilingual speaker are interconnected with each other and the links connecting translation equivalents should not be different from those linking semantically related concepts. We realize, of course, that other versions of the wordinterconnection model could generate different predictions. However, because the word-interconnection model and the concept-mediation model described above can make unambiguous and distinctively different predictions, we will temporarily focus on these two models. We will return to this issue in the Discussion section.

\section{Method}

Subjects. The participants in this research were 24 ChineseEnglish bilingual speakers (their mean age was about 20 years). They were recruited from the introductory psychology subject pool at The Chinese University of Hong Kong. All the subjects had learned Chinese as their first language and had had over 12 years' training in English at school. They all had normal or corrected-tonormal vision.

Design. The design included three within-subjects factors: language of target item (English with a Chinese prime or Chinese with an English prime), type of target (word or nonword), and prime-target relation (direct translation, semantically related, or semantically unrelated).

Stimuli. Sixty prime-target pairs in Chinese and their translation equivalents in English were used. Forty-five of the pairs were selected from the category norms of Jeng, Lai, and Liu (1973), the word-association norms of Postman and Keppel (1970), and the category norms of Battig and Montague (1969). The remaining 15 pairs were constructed by the experimenters. During the selection and construction of the stimuli, care was taken to ensure that the primes and targets were strongly associated (e.g., CLOCK and WATCH). This was verified with 5 pilot subjects in a free association task. All the words were concrete nouns. These materials were then used to form four sets of 60 prime-target pairs, including Chinese prime-English direct translation or English related target, and English prime-Chinese direct translation or Chinese related target. The unrelated prime-target pairs were constructed by re-pairing the targets with unrelated primes. Finally, following Chen (1984), the Chinese nonword targets were formed by means of changing positions of components in the original characters, whereas the English nonword targets were constructed by means of randomizing letters of the original words. All the nonwords so constructed were meaningless and unpronounceable.

All stimulus items used in the experiment were separately printed on $15 \times 10 \mathrm{~cm}$ white cards for presentation in a Gerbrands G1136 four-field tachistoscope. The Chinese characters were printed in boldface type, and the English words were printed in uppercase block letters. From the subject's viewing distance of approximately $72 \mathrm{~cm}$, a Chinese character subtended about $1.2^{\circ}$ of visual angle in width and in height, and a five-letter English word subtended about $2.1^{\circ}$ in width and about $.56^{\circ}$ in height.

Procedure. The subjects were tested individually in a 1-h session. The experimental session consisted of two blocks (Chinese-English or English-Chinese pairs), with 30 pairs of items presented in each block (18 word trials and 12 nonword trials). The order of these different blocks was counterbalanced across subjects. Within each block, three different kinds of item pairs were presented (i.e., direct translation, semantically related, and semantically unrelated items), with 6 item pairs for each kind. The order of different item pairs within each block was randomized. Each of the 60 target and prime items appeared equally often in each prime condition across subjects.

At the beginning of each experimental block, instructions and six practice trials were given to familiarize the subjects with the experimental procedure and the characteristics of that particular block. Each trial began with the presentation of a star signal for $1 \mathrm{sec}$ in the center of the visual field, followed immediately by the display of a prime item for $300 \mathrm{msec}$ in a position about $.5 \mathrm{~cm}$ above the center. The prime was followed immediately by a target item for $2 \mathrm{sec}$ in a position about $.5 \mathrm{~cm}$ below the center. In each trial, the subject's task was to decide whether the presented target was a word or not. The instruction was to respond as accurately and as quickly as possible by pressing either a "YES" or a "NO" button on the response box.

\section{Results}

Word targets. The reaction time (for correct responses) and error rate results for word targets are summarized in Figure 2. These data were subjected to separate analyses of variance (ANOVAs) with two within-subjects factors (target language and prime-target relation). Post hoc 


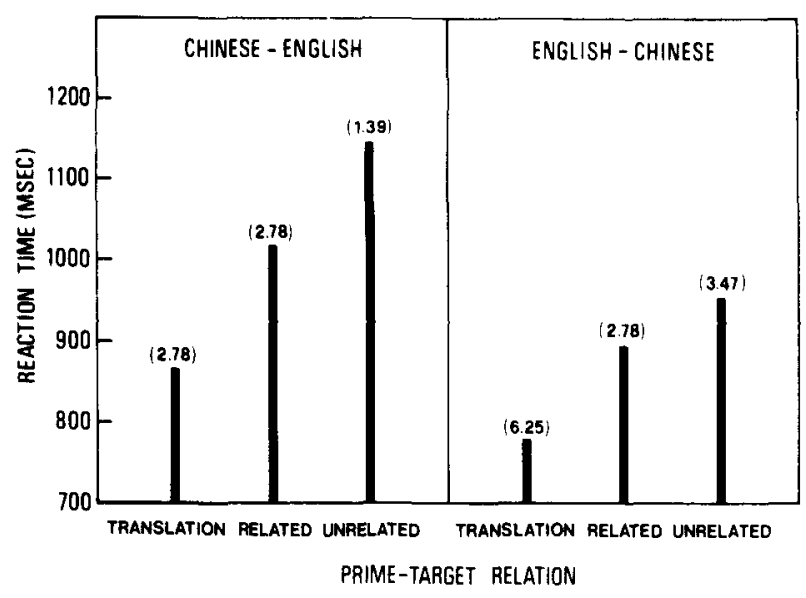

Figure 2. Mean response times as a function of target language and prime-target relation in Experiment 1 (error rates in parentheses).

comparisons were conducted using the protected $t$-test procedure (Fisher's least significant difference).

In the reaction time data, the most important result was the effect of prime-target relation $\left[F(2,46)=36.5, M S_{\mathrm{e}}\right.$ $=17,007, p<.005]$. The direct translation pairs produced faster responses than did the semantically related pairs $[M \mathrm{~s}=822$ and $955 \mathrm{msec}$, respectively; $t(46)=$ 3.53], and the semantically related pairs resulted in faster responses than did the unrelated pairs $[M=1,048 \mathrm{msec}$; $t(46)=2.48]$, with both $p s<.02$. Moreover, the effect of target language indicates that English-Chinese pairs produced faster responses than did Chinese-English pairs $\left[F(1,23)=9.67, M S_{\mathrm{e}}=63,576, p<.005\right]$. The interaction between pair condition and prime-target relation, however, was not significant $[F(2,46)=2.29]$.

Finally, as is shown in Figure 2, the error rates were generally very low in each condition, and no significant results were found in the error data (all $F_{\mathrm{s}}<1.85$ ).

Nonword targets. Latencies to English nonword targets were generally longer than latencies to Chinese nonword targets $(1,248 \mathrm{msec}$ for English targets and $910 \mathrm{msec}$ for Chinese targets). Error rates were in the same direction as latencies (12.15\% for English targets and $2.78 \%$ for Chinese targets).

\section{Discussion}

By using a between-language priming paradigm with a short priming interval of 300 -msec SOA, in the present experiment we demonstrated reliable effects of both translation and semantic priming. The semantic priming effect is consistent with the findings reported previously by Kirsner et al. (1984, Experiments 4 and 5) and Schwanenflugel and Rey (1986). The translation priming effect differed from previous results (see, e.g., Kirsner et al., 1980; Kirsner et al., 1984, Experiments 1 and 3; Scarborough et al., 1984), presumably because of the difference in time lag between the presentations of the prime and the target (i.e., a relatively long lag of about $33 \mathrm{~min}$ in their study and a very short lag of $300 \mathrm{msec}$ in the present experiment). These results are consistent with the idea that between-language transfer is very transient (Kirsner et al., 1984; Scarborough et al., 1984).

In addition to the interval between the prime and the target, translation activities during encoding also affect between-language transfer in a lexical decision priming task. Kirsner et al. (1984), for example, found a reliable translation facilitation effect when subjects were specifically required to engage in translation activities during the presentation of the prime. In the present experiment, however, a short prime-target interval was used. This particular interval (300-msec SOA) was used to ensure that the cue could be clearly read, but that it would be too short for effortful, attentional processing, such as active translation, of a prime to take place (Schwanenflugel \& Rey, 1986; Simpson \& Burgess, 1985). In fact, using both 300 and 100-msec SOAs, Schwanenflugel and Rey demonstrated very similar patterns of effects in lexical decision priming. Moreover, the subjects in the present experiment were not instructed to conduct any special activity with the prime; and different types of prime-target pairs (direct translation, semantically related, and semantically unrelated items) were presented in a mixed rather than blocked order. Thus, it does not seem likely that translation anticipation or other conscious, effortful strategies during encoding of the prime were a major factor in the present findings of the between-language facilitation effects.

Another interesting finding in the present experiment was that the translation priming effect was significantly greater than the semantic priming effect (see Jin \& Fischler, 1987, for a similar finding with 150 -msec SOA). The subjects' lexical decision responses were much faster when primed with a translation than with a semantically related interlingual word. This result was exactly what the concept-mediation model would predict, but it is not consistent with the prediction of the word-interconnection model reviewed in connection with the study of Kirsner et al. (1984). This is because the word-interconnection model does not distinguish between links that join translation equivalents from those which connect semantically related concepts. However, one might argue that the present findings can also be accounted for by another version of the word-interconnection model, which would allow direct translation links to be stronger or better developed than between-language links. This is a reasonable possibility, because the use of translation equivalents to acquire words in a new language is a common practice, and network models of memory (e.g., Collins \& Loftus, 1975 ) include the assumption of link strength. On the other hand, Schwanenflugel and Rey (1986) found that semantic priming was not affected by the semantic distance between the prime and the target. Because the conceptmediation model and the word-interconnection model 
could not be clearly differentiated on the basis of the findings in Experiment 1, we conducted Experiment 2 in order to explore this issue further.

\section{EXPERIMENT 2}

Previously, Schwanenflugel and Rey (1986) demonstrated equal semantic facilitation across and between languages with Spanish-English bilingual speakers; and Vanderwart (1984) reported that pictures and within-language primes produced similar semantic facilitation with English monolinguals. These results were interpreted as supporting the concept-mediation model. However, the conceptmediation model for bilingual speakers proposes that not only between- and within-language lexical items but also images are connected by means of an amodal conceptual system (see, e.g., Chen \& Leung, in press; also Potter, So, Von Eckardt, \& Feldman, 1984). Thus a more rigorous way of testing the concept-mediation model with the semantic priming paradigm would be to include between-language, within-language, and pictorial primes (Kroll \& Potter, 1984). The model predicts similar semantic facilitation across both languages and input forms, a prediction that is tested for the first time in the present Experiment 2.

In addition to testing the concept-mediation model, the second experiment was also designed to test a wordinterconnection model that allows variation in link strength. This model assumes that the within-language links are stronger than between-language links connecting semantically related words (Kirsner et al., 1984). Furthermore, it seems reasonable to predict, on the basis of the model, that both the within- and the between-language links connecting linguistic items should be stronger than the between-form links joining linguistic and nonlinguistic items. In other words, according to the wordinterconnection model, one would expect to find that a within-language prime should produce the greatest semantic facilitation effect and a between-form prime should produce the weakest semantic facilitation.

\section{Method}

Subjects. Twenty-four Chinese-English bilingual speakers (their mean age was about 20 years) participated for research credit in an introductory psychology course at The Chinese University of Hong Kong. None of them had participated in Experiment 1. Their language background was the same as that of the subjects in Experiment 1 , and they all had normal or corrected-to-normal vision.

Design. The design included four within-subjects factors: language of target (Chinese or English), type of prime (Chinese word, English word, or picture), type of target (word or nonword), and prime-target relation (semantically related or unrelated).

Stimuli. Forty-eight prime-target pairs in Chinese and their translation equivalents in English were used. These stimuli were selected from the materials used in Experiment 1. In addition, corresponding line drawings of all the primes were obtained. About three fifths of the line drawings were selected from the standard set of pictures of Snodgrass and Vanderwart (1980); the rest were constructed by the authors. Five pilot subjects had no difficulty in identifying these pictorial materials.

A set of 48 semantically unrelated pairs in each language was formed by re-pairing the targets and primes of the related pairs, so that none of the newly formed pairs seemed semantically related (e.g., CAT and KEY). Furthermore, corresponding nonwords were constructed for all targets. The nonword targets were constructed by means of reordering the components or letters of the original words.

All the stimulus items used in Experiment 2 were separately prepared for presentation with slides. All the Chinese characters were printed in boldface type, and the English words were printed in uppercase block letters. From the subject's viewing distance of approximately $200 \mathrm{~cm}$, a Chinese character subtended about $1.32^{\circ}$ of visual angle in width and in height, a five-letter English word subtended about $1.98^{\circ}$ in width and about $.5^{\circ}$ in height, and a picture subtended about $1.65^{\circ}$ in width and $1.32^{\circ}$ in height.

Apparatus. Two Kodak Ektagraphic projectors (Model AF-2K) with Lafayette shutters were used to present the stimuli. These devices were connected to a Gerbrands tachistoscope controller (Model G1290) for sequence control. In each trial, the display of a target item automatically activated a Lafayette stop clock (Model 54014). This clock was connected to a response box, so that the clock could be stopped by pressing the keys on the response box.

Procedure. The subjects were individually tested in a 1-h session. The experimental session consisted of six blocks of 16 pairs of items. These blocks were formed by a combination of three types of prime (Chinese word, English word, and picture items) in two target languages (Chinese and English). The order of these blocks was counterbalanced across subjects. Within each block, four different kinds of item pairs, formed by the combination of two prime-target relations (including semantically related and unrelated) and two types of target (words and nonwords), were presented, with 4 item pairs for each kind. The order of different item pairs within each block was randomized.

Note that all targets were generated from 48 concepts. Each of the concepts could form four possible targets (one word in Chinese, another in English, and the corresponding nonwords derived from the two words). For a given concept, the Chinese word and the corresponding English nonword were used in two separate trials as targets for half the subjects, and the English word and the corresponding Chinese nonword were used for the other subjects. In other words, each word or nonword target could only appear once for a given subject. Similarly, all primes of three different forms (Chinese word, English word, and picture) were based on 48 concepts. Each of these concepts appeared twice (once in a semantically related trial and once in an unrelated trial, always in different forms), for each subject. Each prime item occurred equally often in a given form across subjects.

Each experimental block began with instructions and four practice trials to familiarize the subjects with the experimental procedure and characteristics of that particular block. Each trial began with the presentation of a "beep" signal for $1 \mathrm{sec}$, followed immediately by the display of a prime item for $300 \mathrm{msec}$. The prime was followed immediately by a target item for $2 \mathrm{sec}$ in a position about $4 \mathrm{~cm}$ lower than the position for the prime. In each trial, the subject's task was to decide whether the presented target was a word or not. The instruction was to respond as accurately and as quickly as possible by pressing either a "YES" or a "NO" button on the response box.

\section{Results and Discussion}

The reaction time (for correct responses) and error rate results for word targets are summarized in Figure 3. The 


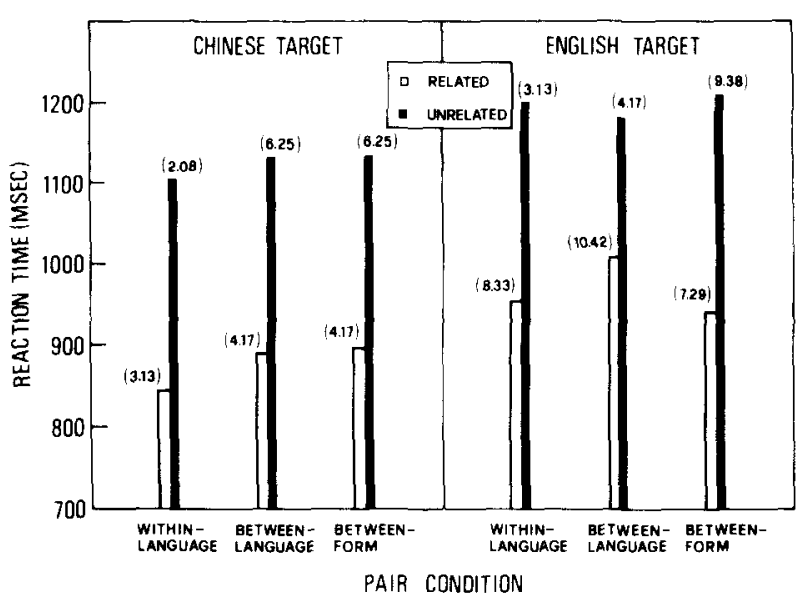

Figure 3. Mean response times as a function of pair condition, target language, and prime-target relation in Experiment 2 (error rates in parentheses).

results for nonword targets are shown in Table 1. Since Experiment 2 was conducted to investigate possible priming effects for word targets in different conditions, only the results for the word trials were analyzed.

Nonword targets. Mean latencies to English nonwords were generally longer than latencies to Chinese nonwords $(1,142 \mathrm{msec}$ for Chinese nonwords and 1,208 $\mathrm{msec}$ for English nonwords; their corresponding error rates were $5.38 \%$ and $4.34 \%$, respectively). Furthermore, latencies for nonwords primed by between-language words were generally longer than those primed by within-language words or pictures (mean latencies were 1,212, 1,145, and $1,169 \mathrm{msec}$; the average error rates were $3.91 \%, 3.65 \%$, and $7.03 \%$, respectively).

Word targets. The reaction time and error data were submitted to two separate ANOVAs with three withinsubjects factors (target language: Chinese or English; prime-target relation: semantically related or unrelated; and pair condition: within-language, between-language, or between-form). Post hoc comparisons were conducted using the protected $t$-test procedure.

The analysis for the error rate data yielded only one significant effect, for target language $[F(1,23)=4.43$, $\left.M S_{\mathrm{e}}=125\right]$. Chinese targets resulted in lower error rates than did English targets. This result suggests that the subjects were not quite as proficient in English as in Chinese.

To investigate whether a speed-accuracy tradeoff might have masked an effect of pair condition, correlations between the reaction times and error rates across $12 \mathrm{ex}$ perimental conditions were computed for each subject.

Table 1

Mean Response Times for Nonword Trials As a Function of Pair Condition and Target Language in Experiment 2

\begin{tabular}{lccc}
\hline & \multicolumn{3}{c}{ Pair Condition } \\
\cline { 2 - 5 } & Within-Language & Between-Language & Between-Form \\
\hline Chinese & $1,095(3.65)$ & $1,184(3.65)$ & $1,149(8.85)$ \\
English & $1,195(3.65)$ & $1,240(4.17)$ & $1,190(5.21)$ \\
\hline
\end{tabular}

Note-Error rates are given in parentheses.
If the subjects had indeed traded accuracy for speed in these conditions, then we should have been able to find many significant, negative correlations. However, no such results were found: none of the correlations was significant [average correlation, $r(10)=.009$ ]. Moreover, there were 11 negative correlations (the average correlation was -.28 ) and 13 positive correlations (the average correlation was .25), indicating that these correlations were only chance correlations (otherwise more than 12 negative correlations would be expected).

The analysis for the reaction time data revealed a significant main effect for prime-target relation $[F(1,23)=$ $\left.334.36, M S_{\mathrm{e}}=12,245, p<.001\right]$. The responses to targets preceded by semantically related primes were about $240 \mathrm{msec}$ faster than the responses to targets preceded by unrelated primes. Chinese targets were responded to about $82 \mathrm{msec}$ faster than English targets $\left[F(1,23)=17.88, M S_{\mathrm{e}}\right.$ $=27,187, p<.001]$. Neither pair condition nor any interaction involving this factor was significant, indicating that the magnitudes of the semantic priming effects in various pair conditions for both Chinese and English targets were quite comparable (see Figure 3 ).

The most crucial finding in Experiment 2 was that, contrary to the prediction of the word-interconnection model, all types of prime-between-language, within-language, and between-form-resulted in comparable semantic facilitation. Rather, the present findings are in line with the concept-mediation model and bear a strong resemblance to the major results of previous studies. Both Schwanenflugel and Rey (1986) and Kirsner et al. (1984, Experiment 4) reported equivalent semantic facilitation for both between- and within-language primes, and Vanderwart (1984) demonstrated similar results with pictures and within-language primes. Taken together, the converging evidence suggests that the amount of semantic facilitation in lexical decision priming is not affected by the surface form of a prime, and that there seems to be an amodal conceptual system that can be accessed by different surface forms.

One notable difference between the present results and those in previous studies can be found in the magnitude of the semantic priming effect; we found a difference of over $200 \mathrm{msec}$ between related and unrelated pairs, whereas others have found a smaller difference (from 15 to $91 \mathrm{msec}$; see, e.g., Jin \& Fischler, 1987; Kroll \& Potter, 1984; Schwanenflugel \& Rey, 1986; Vanderwart, 1984). Our finding of relatively large semantic priming, however, is not without precedent. Kirsner et al. (1984, Experiment 4), using Hindi-English bilingual speakers as subjects, reported large effects of semantic facilitation in lexical decisions with simultaneous presentations of a prime and a target. In that experiment, semantic priming effects ranged from $79 \mathrm{msec}$ for English/English word pairs to $255 \mathrm{msec}$ for English/Hindi word pairs. Note that there are many procedural differences (e.g., type of bilingual subjects, prime-target interval, mixed or blocked presentation of different primes, presentation of prime and target at the same location or at different locations, and 
the proportion of trials with related as opposed to unrelated pairs) in the studies of bilingualism mentioned. However, none of these procedural differences can unambiguously differentiate the studies of bilingualism that have demonstrated large magnitudes of semantic facilitation from those which have not. In other words, at the present moment, it is not clear what factors are responsible for the magnitude of semantic priming in studies of bilingualism.

There is one additional point to note regarding the manipulation of the surface form of a prime. In the present experiment, we found no evidence that lexical decisions for related or unrelated pairs were affected by the surface form of a prime. Vanderwart (1984), on the other hand, reported a reliable effect of prime form for unrelated pairs (i.e., lexical decisions in trials with picture primes were generally slower than those with word primes) and a similar but less reliable effect for related pairs. Because these two studies differed in many respects (e.g., subjects, pair conditions, and target languages), it is not clear whether these differences could have independently or jointly contributed to the different findings in the two studies. However, even when relatively comparable subjects and materials have been used, previous studies on similar topics have also failed to yield very consistent results. For example, Kroll and Potter (1984), in a manner similar to Vanderwart's (1984), adopted English monolingual subjects, and English words, English nonwords, and pictorial materials. Kroll and Potter found that response latencies to make lexical decisions about words were faster than response latencies to make object decisions about pictures of objects for semantically related but highly associated prime-target pairs (e.g., dog-cat), but an opposite pattern (i.e., pictures were faster than words) was found for semantically related but not highly associated pairs (e.g., apple-banana). They further demonstrated that for unrelated pairs in the "semantically related and associated" condition, words were faster than pictures, but words and pictures were equally fast for unrelated pairs in the "semantically related only" condition. Therefore, it seems that the possible effects of the surface form of a stimulus on response latency in decision tasks remain an open question. Further research is needed to explore this issue.

\section{GENERAL DISCUSSION}

The results of the present experiments reveal translation and semantic facilitation effects in Chinese-English bilingual speakers. Specifically, Experiment 1 showed that lexical decision facilitation from the translation primes was greater than that from the between-language semantically related primes. Experiment 2 further demonstrated that the degree of semantic facilitation from within- and between-language primes and that from between-form pictorial primes were comparable.

Previous researchers (e.g., Kirsner et al., 1984; Scarborough et al., 1984; see Kirsner, 1986, for a review) have failed to find a translation facilitation in a lexical decision priming task, whereas in the present study, we have successfully demonstrated such an effect (see Jin \& Fischler, 1987, for similar findings). Although there are many procedural differences between the present study and the previous ones, one crucial factor may be the time interval between the first and the second presentation of the repeated item (see Kirsner et al., 1984, for a discussion of this issue). In the previous studies (e.g., Kirsner et al., 1984), the items generally have been repeated with a relatively long lag, whereas in the present study and in the study of Jin and Fischler, the time interval was very short. Considered together, these results seem to support the idea that between-language facilitation is functional only for a relatively short period (see, e.g., Kirsner et al., 1984; Scarborough et al., 1984).

The present findings are not consistent with the predictions developed on the basis of the word-interconnection model (see Kirsner et al., 1984). To account for the advantage of translation over semantic facilitation obtained in Experiment 1, the word-interconnection model needs to include the assumption that links between translation equivalents are stronger than between-language links. However, by including the assumption of different link strengths, the model does not seem able to account for the findings of Experiment 2, in which semantically related items, regardless of their surface form, yielded similar effects of priming facilitation. The relative strengths of the links presumably depend on people's experience, and thus it seems unlikely that semantically related items of similar and different forms are all associated with similar strengths of links.

On the other hand, the results of the present study can easily be accounted for by the concept-mediation model. This model assumes that words in the two langauges, and pictures, are all mentally connected by means of an amodal conceptual system, and that on the basis of these links to concepts, subjects can actually respond to various kinds of tasks involving the processing of pictures and words, such as lexical decision and naming (Potter et al., 1984; Schwanenflugel \& Rey, 1986; Vanderwart, 1984; see also Snodgrass \& McCollough, 1986, who have used a similar model to account for both modality-specific and modality-free effects of the surface form). Thus, in Experiment 1 , the greater facilitation found in the translation than in the semantic priming condition was presumably due to the fact that translation equivalents activated only a single conceptual node, whereas semantically related items activated two conceptual nodes. In addition, according to the model, a single common conceptual code should be accessed by different surface forms. It is therefore not surprising that the results of Experiment 2 indicated that semantic priming effects were not affected by the visual presentation format of a prime. Although similar results have also been reported by previous researchers (see, e.g., Schwanenflugel \& Rey, 1986; Vanderwart, 1984), we believe our experiment is the first to demonstrate equivalent pictorial, within-language, and betweenlanguage priming for targets in both languages. 
In the present experiments, we tested two major models of bilingual processing. Other models were not tested. These include, for example, the model in which withinlanguage words are directly connected, whereas betweenlanguage words (translation equivalents and related words) are linked through amodal concepts. An alternative model would be that mental representations of different forms are all interconnected and are also linked to the amodal concepts. Such models, similar to the word-interconnection model, would predict that semantic facilitation from within-language conditions should be greater than it would be from between-language conditions, and that withinform conditions should create stronger transfer than do between-form conditions. However, the present findings of comparable priming effects for different types of primes are not consistent with these predictions. Thus, the present findings provide no support for these models as explanations of semantic priming in bilingual speakers.

Most previous studies have included bilingual subjects whose first and second languages were both alphabetic scripts (e.g., English, French, Spanish, German), whereas the present study adopted bilingual speakers whose languages were very distinct (logographic Chinese and alphabetic English). Recently, Chen and Ho (1986) have discussed this issue of language similarity (see also Aaronson \& Ferres, 1986, for a relevant discussion) and presented evidence to indicate that this factor could affect the pattern of between- and within-language colornaming interference in bilingual speakers. Consequently, one might ask whether language similarity (or betweenlanguage distance) could have affected the present findings. This does not seem to be the case, however, because the major patterns of the semantic facilitations demonstrated in the present and other relevant studies (e.g., Schwanenflugel \& Rey, 1986; Vanderwart, 1984) are comparable, although these studies used subjects with very different linguistic experiences (i.e., Chinese-English and Spanish-English bilinguals and English monolinguals). Rather, the consistent patterns suggest that mental processes involved in the semantic priming paradigm and the lexical decision task are universal, and independent of between-language distance.

Finally, traditional studies of lexical processing in bilinguals have focused on whether bilinguals have one or two lexicons (i.e., the interdependence versus independence or single- versus dual-code debate; see, e.g., McCormack, 1977). Unfortunately, the results of these studies are indeterminate, possibly because the different tasks used (see, e.g., Grosjean, 1982; Snodgrass, 1984, for relevant discussion). Durgunoglu and Roediger (1987) recently reported compelling evidence that the specific conditions of testing are the main determinants of whether the pattern of language interdependence or independence is observed in studies of bilingualism. The present study, following previous studies on similar topics, adopted the lexical decision priming task to minimize the possible confounding of task. Thus, we have limited our discussion to the context of this particular task. However, the lexi- cal decision task has been shown to be sensitive to both automatic semantic processes and attentional strategic processes, especially when longer SOAs are used (see, e.g., Fischler, 1977; Neely, 1977; Simpson \& Burgess, 1985). In this respect, it would seem worthwhile to replicate the present study with a naming task that might be less likely to be affected by task-specific strategies (see Balota \& Lorch, 1986, for relevant results and discussion).

\section{REFERENCES}

Aaronson, D., \& Ferres, S. (1986). Sentence processing in ChineseAmerican bilinguals. Journal of Memory \& Language, 25, 136-162.

Balota, D. A., \& LorCH, R. F., JR. (1986). Depth of automatic spreading activation: Mediated priming effects in pronunciation but not in lexical decision. Journal of Experimental Psychology: Learning, Memory, \& Cognition, 12, 336-345.

Battig, W. F., \& Montague, W. E. (1969). Category norms for verbal learning items in 56 categories: $A$ replication and extension of the Connecticut category norms. Journal of Experimental Psychology Monographs, 80(3, Pt. 2), 1-45.

CHEN, H.-C. (1984). Detecting radical components of Chinese characters in visual reading. Chinese Journal of Psychology, 26, 29-34.

CheN, H.-C., \& Ho, C. (1986). Development of Stroop interference in Chinese-English bilinguals. Journal of Experimental Psychology: Learning, Memory, \& Cognition, 12, 397-401.

Chen, H.-C., \& LeUnG, Y. S. (in press). Patterns of lexical processing in a non-native language. Journal of Experimental Psychology: Learning, Memory, \& Cognition.

Colluns, A., \& Loftus, E. (1975). A spreading activation theory of semantic processing. Psychological Review, 82, $407-428$.

Durgunoglu, A. Y., \& Roediger, H. L. (1987). Test differences in accessing bilingual memory. Journal of Memory \& Language, 26, 377-391

Feldman, L. B., \& Moskovljevic, J. (1987). Repetition priming is not purely episodic in origin. Journal of Experimental Psychology: Learning, Memory, \& Cognition, 13, 573-581.

Fischler, I. (1977). Semantic facilitation without association in a lexical decision task. Memory \& Cognition, 5, 335-339.

Grosjean, F. (1982). Life with two languages: An introduction to bilingualism. Cambridge, MA: Harvard University Press.

Hornby, P. A. (Ed.) (1977). Bilingualism: Psychological, social, and educational implications. New York: Academic Press.

JenG, C. I., LAI, M. W., \& LIU, I. M. (1973). Category norms in Chinese and English from bilingual subjects. Acta Psychologica Taiwanica, 15, 81-153.

JIN, Y.-S., \& FischleR, I. (1987, March). Effects of concreteness on cross-language priming of lexical decision. Paper presented at the Southeastern Psychological Association meeting, Atlanta, GA.

KIRSNER, K. (1986). Lexical function: Is a bilingual account necessary? In J. Vaid (Ed.), Language processing in bilinguals: Psycholinguistic and neuropsychological perspectives (pp. 21-45). Hillsdale, NJ: Erlbaum.

Kirsner, K., Brown, H. L., Abrol, S., Chadha, N. N., \& Sharma, N. K. (1980). Bilingualism and lexical representation. Quarterly Journal of Experimental Psychology, 4, 585-594.

Kirsner, K., Smith, M. C., Lockhart, R. S., King, M. L., \& JAIN, M. (1984). The bilingual lexicon: Language-specific units in an integrated network. Journal of Verbal Learning \& Verbal Behavior. 23, 519-539.

Kroll, J. F., \& Potter, M. C. (1984). Recognizing words, pictures, and concepts: A comparison of lexical and reality decisions. Journal of Verbal Learning \& Verbal Behavior, 23, 39-66.

McCormack, P. D. (1977). Bilingual linguistic memory: The independence-interdependence issue revisited. In P. A. Hornby (Ed), Bilingualism: Social and educational implications (pp. 57-66). New York: Academic Press.

NeEt. 1. H. (1977). Semantic priming and retrieval from lexical 
memory: Roles of inhibitionless spreading activation and limited capacity attention. Journal of Experimental Psychology: General, 106, 226-254.

Postman, L., \& KePpel, G. (Eds.). (1970). Norms of word association. New York: Academic Press.

Potter, M. C., So, K.-F., Von Eckardt, B., \& Feldman, L. B. (1984). Lexical and conceptual representation in beginning and proficient bilinguals. Journal of Verbal Learning \& Verbal Behavior, 23, 23-38.

Scarborough, D. L., Cortese, C., \& Scarborough, H. (1977). Frequency and repetition effects in lexical memory. Joumal of Experimental Psychology: Human Perception \& Performance, 3, 1-17.

Scarborough, D. L., Gerard, L., \& Cortese, C. (1984). Independence of lexical access in bilingual word recognition. Journal of Verbal Learning \& Verbal Behavior, 23, 84-99.

SCHWANENFLUGEL, P. J., \& ReY, M. (1986). Interlingual semantic facilitation: Evidence for a common representational system in the bilingual lexicon. Journal of Memory \& Language, 25, 605-618.

Simpson, G. B., \& Burgess, C. (1985). Activation and selection processes in the recognition of ambiguous words. Journal of Experimental Psychology: Human Perception \& Performance, 11, $28-39$. SNodgrass, J. G. (Ed.). (1984). Concepts and their surface representations [Special issue]. Journal of Verbal Learning \& Verbal Behavior, 23(1).

Snodgrass, J. G., \& McCullough, B. (1986). The role of visual similarity in picture categorization. Joumal of Experimental Psychology: Learning, Memory, \& Cognition, 12, 147-154.

SNOdGrass, J. G., \& VANDERWART, M. (1980). A standardized set of 260 pictures: Norms for name agreement, image agreement, familiarity, and visual complexity. Joumal of Experimental Psychology: $\mathrm{Hu}$ man Learning \& Memory, 6, 174-215.

VAID, J. (Ed.). (1986). Language processing in bilinguals: Psycholinguistic and neuropsychological perspectives. Hillsdale, NJ: Erlbaum.

VANDERWART, M. (1984). Priming by pictures in lexical decision. Journal of Verbal Learming \& Verbal Behavior, 23, 67-83.

(Manuscript received January 11, 1988; revised manuscript accepted for publication October 14, 1988.)

\title{
Announcement
}

\author{
International Congress of Psychology \\ Brussels, Belgium \\ July 19-24, 1992
}

The next International Congress of Psychology will be held in Brussels, July 19-24, 1992, under the auspices of the International Union of Psychological Science (IUPsyS).

Congress brochures may be obtained from Brussels International Conference Centre, Place des Expositions, Place de Belgique, B-1020 Brussels, Belgium (FAX 32247880 23).

Proposals for the Scientific Program, including symposia, may be sent to the U.S. member of IUPsyS, the National Academy of Science. They should be addressed to Pamela Ebert Flattau, USNC/IUPsyS, National Research Council, GH 186, 2101 Constitution Avenue, N.W., Washington, D.C. 20418. 